\title{
Advanced Malignant Mesothelioma
}

National Cancer Institute

\section{Source}

National Cancer Institute. Advanced Malignant Mesothelioma. NCI Thesaurus. Code C7865.

A malignant mesothelioma that has spread beyond its original site of growth. 